\title{
Food and Beverage Serving Workers
}

National Cancer Institute

\section{Source}

National Cancer Institute. Food and Beverage Serving Workers. NCI Thesaurus. Code C122460.

Workers who perform a variety of customer service, food preparation, and cleaning duties in restaurants, cafeterias, and other eating and drinking establishments. 